\title{
Analysis and Treatment of High Exhaust Temperature of Marine Generator
}

\author{
Zhaoqiang $\mathrm{Li}^{1, \mathrm{a}_{*}}$ and Baocheng $\mathrm{Lu}^{1, \mathrm{~b}}$ \\ ${ }^{1}$ Binzhou Polytechnic No.919, Huanghe 12 Road, Binzhou, Shandong Province, China \\ areaderlzq@163.com, b176816963@qq.com
}

Keywords: Fault tree analysis, Exhaust temperature high, Analysis and treatment

\begin{abstract}
A fault tree of high exhaust temperature is constructed according to the theoretical and practical analysis of the exhaust temperature of a marine generator. The air system and fuel system are analyzed and judged, and the fault tree analysis method combined with the actual situation is used in troubleshoot of the system. Study results show that the fault tree analysis method is convenient, fast, simple and reliable for diagnosing and judging faults.
\end{abstract}

\section{Introduction}

Many ships use MAN B\&W L20/27 diesel engine as the marine generator, which can meet the demand of power supply for the ship sailing when the new factory is out of the factory. But with the increase of operation time, natural wear of moving parts of the machine itself the influences of factors on the lack of management, the performance of the engine is decreased gradually, the exhaust temperature rises gradually, the ship's safety and economy is getting worse, many can not realize the single motor sailing ship.

The method of fault tree analysis to typical fault events as the top event through the middle and basic events, a network diagram of the cause of the accident, in strict accordance with the logical analysis of the ideas, simple graphics, logic through the relationship between, it can quickly find the cause of the fault.

\section{Fault phenomenon}

One day the duty engineer Tours of inspection, check no.1 generator, and found that the 4 cylinder exhaust temperature $580{ }^{\circ} \mathrm{C}, 50{ }^{\circ} \mathrm{C}$ higher than the average temperature of each cylinder, carefully check the fuel, lubricating oil, cooling water pressure and temperature are normal. The engineer promptly started the backup generator. Uninstall 1 generator, make it idle, find fault.

\section{Fault analysis}

First, we should judge the fault through the fault phenomenon description for single cylinder exhaust temperature is too high, the reason has the following two categories, the first class air system, a common fault with the exhaust turbocharger compressor end filter, dirty air filter, intake channel blockage, poor effect of inlet valve, intake valve valve clearance of small dirt etc. the second category is the fuel oil;, a common fault with low temperature, fuel injector, oil injection pressure is low, the injection timing is not correct. To sum up, we set the single cylinder exhaust temperature high to the top fault tree event.

\section{Build up the fault tree}

According to the fault tree analysis method, we set up the cylinder exhaust temperature as the top event T, air system and fuel system fault fault are respectively M1 and M2 as the intermediate event, the exhaust turbocharger compressor end filter dirty X1, air filter, air inlet channel blocking effect is 
poor X2 X3, the intake valve gas valve, intake valve clearance X4 dirty X5, low temperature X6, fuel injector, fuel injection pressure and low leakage X7 X8, injection timing is not correct X9 basic events. Among them, X1, X2, X3, X4 and X5 cause intermediate incident, M1 air system failure, X6, X7, X8 and X9 cause intermediate incident, M2 fuel system failure.

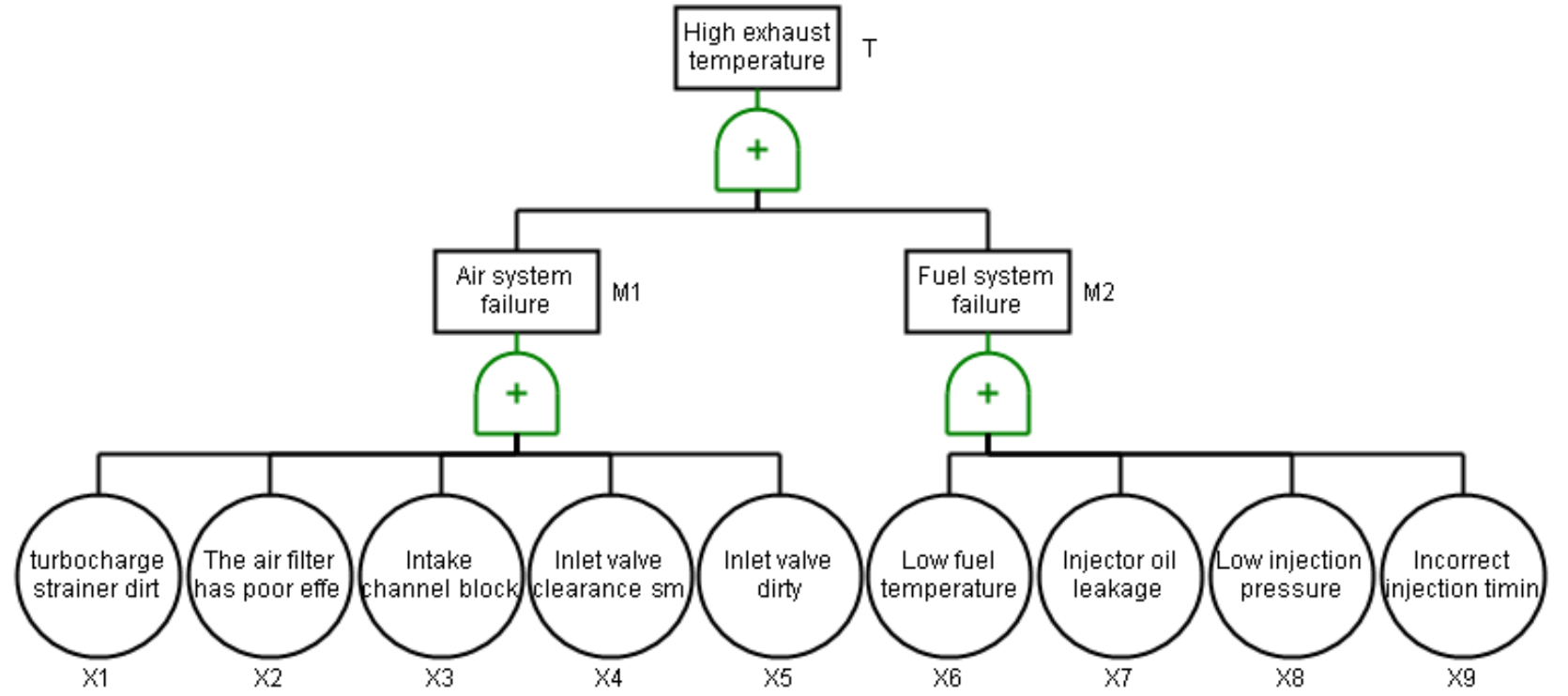

Fig. 1 fault tree of single cylinder exhaust temperature of diesel engine

\section{Troubleshooting}

First of all, we have checked that the exhaust temperature gauge is normal. After analysis, single cylinder exhaust temperature high between the air system and fuel system fault M1 fault M2, because diesel generator maintenance after just 200 hours of operation, we have the basic rule of exhaust gas turbocharger compressor end filter dirty X1, air filter, air inlet channel blocking effect is poor X2 X3, $\mathrm{X} 5$ four dirty air inlet valve fault event. Taking into account the engine only single cylinder exhaust temperature is high, the basic rule of the fuel temperature low X6 basic events, so we suspect that the fault point only intake valve valve clearance X4, injector oil X7, injection pressure, injection timing and low X8 incorrect X9 four basic events. According to the equipment instructions and special tools, we check out one by one.

\section{Determine the air inlet valve clearance is small, whether it is a fault point}

When the generator is in cold state, open the cylinder cover, turning to the high-pressure fuel supply position, using a feeler gauge measurement of inlet valve clearance for the $3.2 \mathrm{~mm}$, to meet the requirements of manual valve clearance, everything is normal.

\section{Determine whether the oil leakage of the injector is a fault point}

When the fuel injector is removed, the test of the starting valve pressure and atomization is carried out. The oil leakage of the injector is measured and the pressure of the opening valve is low. Here is the point of failure. Continue to test to see if there are any other faults.

\section{Determine whether the injection pressure is low or not is a fault point}

After the pressure gauge is installed at the outlet of the high pressure oil pump, the injection pressure is normal.

\section{Determine whether the injection timing is correct or not is a fault point}

No.4 cylinder oil supply timing is measured using oil extraction method, and it is normal. The injector opening pressure adjustment is normal, turning test of injection timing, it is normal

To sum up, the reason for the high exhaust temperature of No. 4 cylinder is the oil leakage of the injector X7. 


\section{Fault repair}

When the fault point is found, the injector shall be replaced in time, and the trouble can be eliminated. The following tasks should be done to ensure high temperature and ventilation avoidance.

The ventilation quality should be in good condition so that the supercharger, air cooler, intake and exhaust valve and piston gas ring are in normal condition to ensure sufficient fresh air in the cylinder.

\section{Exhaust gas turbocharger}

Isobaric pressure single-stage radial turbine driven coaxial single-stage centrifugal compressor, the sliding bearing floating bearing, lubricating oil supply system by the diesel engine, the supercharger speed is high, is very sensitive to the clean degree. Therefore, it is important to keep the turbocharger impeller, compressor impeller and air cooler from fouling. No automatic flushing device of the machine, it is recommended at least every three months cleaning a compressor impeller and silencer, filter cleaning once a week; every half year dismantling and cleaning the nozzle ring, turbine blades, oil seal, oil return pipe, check and measure the bearing wear, to ensure the smooth and the exhaust gas turbocharger does not leak (the siphon phenomenon will lead to increased exhaust back pressure), also should pay attention to not long time at low load operation.

\section{Air cooler}

As the operation environment of the machine is poor, the air side of the air cooler is polluted by oil and gas, which affects the circulation of compressed air. The sludge in the water chamber causes obstruction and reduces the flow rate, resulting in a decrease in the cooling effect of the pressurized air. As everyone knows, the diesel engine when each increase of intake air temperature 1 degrees $C$ is about 5 degrees higher exhaust temperature C. In order to keep the intercooler in good working condition, chemical cleaning should be carried out on a regular basis (a self cleaning tank can be made on the ship, chemical cycle and rinse). When installing the intercooler, check the sealing surface of the sealing surface of the scavenging tank to prevent the charging air from entering into the scavenging box through the short circuit of the intercooler.

\section{Inlet and exhaust valve}

The surface of the inlet and exhaust valve is seriously carbon bound, which prevents air from entering and discharging the air cylinder, and reduces the quality of the air exchange. Most of the people who have been inspected have this kind of exclamation. The air valve carbon is sometimes more than half of its circulation path, and the intake valve is much more than the exhaust valve (the exhaust is higher than the intake pressure). This is due to the long-term low load operation, on the other hand, because of the wear between the valve rod and the valve sleeve or the sealing rubber ring in the sleeve failure, the oil leak to the surface of the high temperature valve to form carbon.

Daily management should pay attention to observe the exhaust color; pay attention to each cylinder exhaust temperature measurement and analysis; regularly measured cylinder compression pressure to determine the tightness of the cylinder. It is suggested that the cylinder head shall be suspended for 3000-4000 hours after the conventional lifting cylinder, and the working conditions of the air valve and the sleeve shall be checked and cleaned, the grinding air valve shall be replaced, and the sealing rubber ring for the sleeve can be replaced.

\section{Fuel injection system}

Make sure the fuel injection system works properly. The fuel injection pump should have the correct fuel timing and uniform fuel supply. The injector shall have the correct opening valve pressure and good atomization quality.

Injector regular cleaning, check valve pressure (24MPa) to check the sealing and atomization quality; install the fuel injectors that gasket injector hole, to prevent the existence of multiple injector gasket makes up, affecting the formation of mixed gas.

Measurement of timing: because the operation of the machine to make the roller cam working surface, lifting mechanism and other parts wear, resulting in injection timing delay, change can be 
measured by the numerical and the exhaust temperature of each cylinder maximum explosion pressure to roughly determine the changes of each cylinder injection timing. 20/27 machine adopts upside down type high pressure pump, if the risk measurement method of oil injection advance angle between the turning and the observer is difficult to achieve the same, so that the measured value error. This paper introduces the measurement methods of the micrometer.

First proofread the top dead center of the first cylinder, the flywheel circumference $2750 \mathrm{~mm}$, the arc length of each degree is $7.64 \mathrm{~mm}$; the 20/27 flywheel has only the top dead center mark of each cylinder, and there are more than one to proofread and mark on the flywheel.

Remove out of the oil valve and fitted with self-made frame gauge.

According to the running direction when turning the dial gauge lift of $4.0 \mathrm{~mm}$ is the start of oil. The oil return hole on the sleeve is $5 \mathrm{~mm}$. When the cam is in the base circle, the plunger has blocked the oil return hole $1 \mathrm{~mm}$. Considering the oil leakage in the plug and the trace compression factor of the oil, the lift can be slightly larger.

Measure the length of the rotating flywheel and calculate the degree of the starting point of the injection.

It is better to compare the two measurements to confirm the difference between the actual and theoretical injection advance angles; to decide whether to change the spare parts or to adjust the injection advance angle.

\section{Adjustment of injection start point}

The machine adopts integral cam shaft. If the angle of fuel injection is adjusted by adopting the method of rotating camshaft, its disadvantage is changing the intake and exhaust timing, and affecting the quality of the ventilation. Two is because the cam and other parts wear different, make each cylinder timing difference. It is recommended to use the lifting piston method, plus the gasket in the roller jacking mechanism, and reduce the gasket at the lower end of the pump body by the sleeve method. Use the above two methods to adjust the injection advance angle, to ensure that the fuel cam in the original effective working section; increase and decrease gaskets to check, when the plunger up to the starting point, must be below the edge of the sleeve.

\section{Conclusion}

The cause of the diesel exhaust temperature may be in many ways, but eventually, after all is not the "gas" is the "oil", as long as we take a realistic attitude, concrete analysis of concrete problems, take reasonable measures, diesel engine exhaust temperature of the problem can be solved. This paper adopts the method of fault tree analysis, will cause two kinds of single cylinder causes the high exhaust temperature is set to the middle event, fault judging method, the theoretical analysis and practical judgment of the rapid processing of fault events, save, save manpower, is conducive to improve the processing speed of the fault.

\section{References}

[1] Peng Chen, Fault analysis and removal of exhaust gas temperature of a ship diesel engine [J]. Journal of Xingtai Polytechnic College.2016.

[2] Chen Qiang, Yang Ming, Research on reliability analysis method based on multi layer model and fault tree[C], Beijing Nuclear Society, 2014.

[3] Zhang Yu, Application of fault tree analysis in aircraft maintenance[J], China Science and technology,2014(15):33-34. 